\title{
The ocular adverse effects of oral drugs
}

\section{SUMMARY}

Some commonly prescribed drugs have ocular adverse effects. Many parts of the eye can be affected by oral drugs. Some ocular adverse effects may be reversed with medical or surgical intervention whereas other drugs may cause irreversible loss of vision.

The risk of visual loss can be reduced by a number of approaches, including monitoring for ocular toxicity, reducing the drug dose, or stopping the drug and looking for an alternative. This can be supported by good communication between the prescribing clinician and ophthalmologist.

Infrequent or delayed ocular adverse effects may not be identified in clinical trials of new drugs. Reporting adverse events is therefore important.

\section{Introduction}

Drugs that are taken orally are systemically absorbed, with the potential to affect all parts of the body including the eye. Its rich blood supply and relatively small mass increase the susceptibility of the eye to drug-related adverse effects.' Many parts of the eye can be affected by oral drugs. Patients presenting with unexplained ocular symptoms should be asked which drugs they are taking. Table 1 shows some of the ocular adverse effects to consider with common orally administered drug classes..$^{2-35}$

\section{Structures of the eye affected by oral drugs}

Drugs may cause symptoms characteristic of specific eye diseases (Table 2). Some drugs, such as those with anticholinergic activity, affect several parts of the eye (see Fig.).

\section{Anterior chamber and cornea}

Anticholinergic drugs cause the relaxation of the ciliary muscle, leading to temporary blurred vision. ${ }^{7}$ They can contribute to dry-eye symptoms by suppressing normal parasympathetic activity. Anticholinergic drugs can also cause the severe adverse effect of angle-closure glaucoma. This usually occurs in long-sighted patients with narrow drainage angles. Angle closure is highly unlikely in patients who have had cataract surgery because removing the lens deepens the anterior chamber.

Bisphosphonates can cause inflammation leading to conjunctivitis, episcleritis, scleritis, keratitis and uveitis. The exact mechanism of this ocular inflammation is not yet known. ${ }^{14}$ Symptoms usually emerge more slowly (usually 6-8 weeks) with oral versus intravenous dosing. Unilateral and bilateral ocular presentations have been reported. ${ }^{14}$ Bisphosphonates may also cause corneal or scleral melting which requires urgent ophthalmology referral.

Amiodarone, and other drugs such as

hydroxychloroquine, can deposit on the basal epithelial layer of the cornea causing the formation of whirl-like corneal microdeposits called vortex keratopathy. ${ }^{3}$ This is usually asymptomatic and does not require stopping the treatment. However, advanced corneal deposits can cause visual symptoms, hence patients should be referred for an ophthalmic review if the keratopathy affects their vision.

Phenothiazines can cause the development of corneal epithelial changes that can eventually result in corneal oedema. The changes of corneal oedema can become permanent if the drug is not stopped promptly. ${ }^{25}$

The long-term use of corticosteroids via any route of administration may increase intraocular pressure by interfering with the outflow from the trabecular meshwork. This is a significant risk factor for the development of glaucoma. ${ }^{19}$

\section{Iris and lens}

Corticosteroids can accelerate cataract progression. Classically, they cause posterior subcapsular cataracts which develop more rapidly than typical age-related nuclear sclerotic cataracts. ${ }^{19}$ This may relate to corticosteroid-induced changes to gene transcription in the epithelial cells of the lens..$^{19}$ The long-term use of allopurinol has also been linked to cataract formation. ${ }^{5}$ The use of alpha, adrenergic receptor antagonists, such as tamsulosin, may lead to the iris becoming mobile during cataract surgery, a phenomenon called intraoperative floppy iris syndrome. ${ }^{2}$ The mechanism is probably related to the blockade of alpha adrenergic receptors within the dilator muscle of the iris. Floppy iris syndrome may increase the likelihood of iris or posterior

\section{Rawan Ahmad iD \\ Pharmacist ${ }^{1}$ \\ Hemal Mehta \\ Ophthalmologist t,2 $^{2}$ \\ Strathfield Retina Clinic, Sydney \\ 2 Save Sight Registries, University of Sydney}

\section{Keywords}

eye, ocular toxicity

Aust Prescr 2021;44:129-36 https://doi.org/10.18773/ austprescr.2021.028

Corrected 13 August 2021

This is the corrected version of the article.

Correction notice available at: https://doi.org/10.18773/ austprescr.2021.045 


\section{Oral drug}

Alpha, adrenergic receptor

antagonists

- tamsulosin

Antiarrhythmics

- amiodarone

\section{- digoxin}

Allopurinol

Anticholinergics including:

- antihistamines

- antipsychotics

- antispasmodics,

e.g. oxybutynin
Anticoagulants
- aspirin
- clopidogrel
- warfarin
- apixaban
- dabigatran
- rivaroxaban
- ticagrelor

\section{Ocular adverse effects}

Intraoperative floppy iris syndrome resulting in the iris becoming mobile during cataract surgery. ${ }^{2}$ This increases the risk of iris damage with greater chance of postoperative blurred vision, sensitivity to light and difficulty driving at night.

Floppy iris syndrome can also increase the risk of damage to the posterior lens capsule - a poor prognostic factor for cataract surgery.

Corneal microdeposits called vortex keratopathy have been reported in most patients.

Amiodarone can rarely cause optic neuropathy which may result in permanent visual loss. ${ }^{3}$

Ocular symptoms include yellowing of vision, scintillating scotoma and blurred

vision. These changes are likely due to direct photoreceptor toxicity.

Long-term use of allopurinol has been associated with the development of cortical and subcapsular cataract formation. ${ }^{5}$

Reduced tear production (dry eyes)

Dilated pupils.?

Management

Usually there is no need to stop the drug as stopping it does not necessarily prevent floppy iris syndrome.

The ophthalmic surgeon can take precautions during cataract surgery if aware the patient is on this class of drug.

Action required

Inform ophthalmic surgeon of present or past drug use if patient is referred for cataract surgery.

Most are asymptomatic and do not require intervention but advanced corneal deposits can cause visual symptoms. ${ }^{3}$

Consider discussing this potential ocular adverse event when prescribing or dispensing.

The visual symptoms usually reverse when digoxin is stopped.

Consider discussing this potential ocular adverse event when prescribing or dispensing.

Consider discussing angle-closure glaucoma when prescribing or dispensing.

Decreased accommodation.

Risk of acute angle-closure glaucoma in patients with narrow angles - this is unlikely to occur if the patient had previous cataract surgery.

Potential haemorrhagic complications during peri-ocular surgery:
Discussion of possible cessation before certain types of surgery such as eyelid surgery. ${ }^{8}$

Anticoagulants do not always need to be stopped before cataract surgery, especially if it is performed under topical anaesthesia. The ophthalmic surgeon should provide guidance.

Anticoagulants are not routinely stopped before intravitreal therapy.
Routine ophthalmology referral only if patient is symptomatic.

Immediate ophthalmology referral if patient has symptoms of optic neuropathy.

Routine ophthalmology referral if patient is symptomatic.

Routine ophthalmology referral if patient is symptomatic.

mmediate ophthalmology referra if angle-closure glaucoma is

suspected.

\section{Otherwise, routine}

ophthalmology referral if ocular symptoms persist after stopping the anticholinergic drug or if it has to continue.?

Immediate ophthalmology referral if there is bleeding in the eye.

Subconjunctival haemorrhage on the surface of the eye usually resolve within 3 weeks and does not require ophthalmology referral if there are no other ocular symptoms. 


\begin{tabular}{ll}
\hline Oral drug & Ocular adverse effects \\
\hline Antiepileptics & Topiramate can cause secondary angle-closure \\
- topiramate & glaucoma hence onset can sometimes be delayed. \\
& Most cases present in the first few weeks of treatment \\
& although some cases are reported within hours \\
& of treatment. ${ }^{9-11}$ \\
& Visual field defects. ${ }^{9}$ \\
& Oculogyric crisis - a dystonic reaction characterised \\
& by prolonged involuntary upward deviation of \\
& the eyes..$^{910}$ \\
& Uveitis. ${ }^{9}$ \\
\hline
\end{tabular}

\section{Management}

Bilateral angle closure should raise suspicions of a secondary angleclosure mechanism. Topical or systemic aqueous suppressants and topical cycloplegics (e.g. tropicamide, cyclopentolate or atropine) are initially used to manage secondary angle closure.

The initial management of primary angle closure is different where, in addition to aqueous suppression, the pupils are constricted with pilocarpine.

\section{Action required}

Immediate ophthalmology referral for symptomatic patients. ${ }^{9}$
- gabapentin

Cases of nystagmus, diplopia and visual field defects have been reported.12

- vigabatrin

Patients can develop visual field constriction attributable to vigabatrin. Patients may not notice visual field loss until the central field is affected.13 Patients can also develop optic atrophy with pallor of the optic nerve head..$^{13}$

Bisphosphonates

- alendronate sodium

- risedronate

- zoledronic acid

Chloroquine-based drugs

- chloroquine

- hydroxychloroquin leading to conjunctivitis, episcleritis, scleritis, keratitis or uveitis. ${ }^{14}$

Corneal and scleral melting have been reported. Symptoms usually emerge more slowly (usually $6-8$ weeks) with oral versus intravenous dosing..$^{14}$

Patients are usually asymptomatic early on but advanced maculopathy or peripheral retinopathy can result in irreversible visual loss. 15-17

Patients who have been taking hydroxychloroquine for a period longer than 5 years or have been taking doses greater than $5 \mathrm{mg} / \mathrm{kg} /$ day are at an increased risk of maculopathy. Renal or liver impairment or concomitant tamoxifen use increase the risk. ${ }^{15-17}$
These drugs can cause inflammation in the eye
The incidence of visual field defects is low and therefore routine eye screening is not widely recommended. An annual computerised visual field test as part of the patient's routine eye check with an optometrist or ophthalmologist is reasonable.

A baseline visual field should be obtained before treatment

Computerised visual field assessment should be repeated every 6 months for 5 years and can be extended to annually thereafter in patients who have no visual field defects.

The visual field defects may not reverse on cessation of the drug but would likely worsen with continued use..$^{13}$

Ocular signs usually abate after stopping the bisphosphonate but might require topical or oral corticosteroids. ${ }^{14}$

Symptoms generally recur upon bisphosphonate rechallenge.

Ocular screening consists of structural imaging such as optica coherence tomography or fundus autofluorescence, and functional tests such as computerised visual fields or less widely available multifocal electroretinograms. ${ }^{15-17}$

Baseline ocular assessment is recommended up to 12 months after starting hydroxychloroquine treatment. Repeat assessment should occur annually after 5 years of treatment or after 12 months in high-risk groups. ${ }^{15-18}$

Chloroquine has a worse adverse effect profile than hydroxychloroquine and all patients on chloroquine require baseline and at least annual ocular monitoring.
Immediate ophthalmology referral is recommended for symptomatic patients.

Ensure patients on vigabatrin are referred for ophthalmology screening.

Corneal and scleral melting require urgent ophthalmology referral.

Conjunctivitis and episcleritis can be referred routinely to ophthalmology.

Ensure patients on chloroquinebased drugs are referred for ophthalmology screening. 


\section{Oral drug}

\section{Corticosteroids}

- prednisolone

- dexamethasone

\section{Ocular adverse effects}

Corticosteroid-induced raised intraocular pressure can lead to glaucoma. ${ }^{19}$ Open-angle glaucoma is asymptomatic until advanced.

Corticosteroids can accelerate cataract progression and cause posterior subcapsular cataracts.

Ethambuto

Fingolimod

Isotretinoin and vitamin $\mathrm{A}$

Ocular surface signs: ${ }^{22}$

- blepharoconjunctivitis

- chalazia

- corneal opacities

- dry eyes.

Retinopathy:22

excess vitamin A may worsen certain retina dystrophies.

MEK inhibitors e.g. crizotinib

Visual disturbances have been reported in patients taking oral MEK inhibitors. Reported ocular adverse effects include:

- decreased visual acuity

- visual field defects

- dry-eye symptoms

- eyelid abnormalities ${ }^{23}$

- retinal vein occlusion

- MEK-associated retinopathy. ${ }^{23}$

\section{Management}

Open-angle glaucoma is usually managed with drops or laser. However, more complicated cases may require surgery.

Intraocular pressure should be monitored by an optometrist with referral to an ophthalmologist if it is raised. Intraocular pressure often returns to normal following cessation of corticosteroids.

Between $30 \%$ and $64 \%$ of patients will show some visual recovery if the optic neuropathy is detected early and the ethambutol is stopped. ${ }^{20}$

Baseline ophthalmology assessment is required. Re-assessment every 3 months while the patient remains on low-dose treatment or every month if the dose is above $15 \mathrm{mg} / \mathrm{kg} /$ day.

Ophthalmic assessment including optical coherence tomography imaging at baseline and then 3-4 months after starting treatment. Ocular surveillance can be annual thereafter or earlier if the patient becomes symptomatic. Fingolimod should ideally not be started within 3 months of intraocular surgery as it can make differentiating postoperative macula oedema from drug toxicity challenging.

Patients with fingolimod-associated macular oedema do not always have to stop the treatment. Stopping may cause a rebound of multiple sclerosis. The macular oedema can often be treated with local therapy.

Visual symptoms should stop with drug cessation if not too advanced. ${ }^{22}$

MEK-associated retinopathy has been reported to improve after drug cessation. ${ }^{23}$
Routine ophthalmology referral if

symptomatic.

\section{Action required}

Routine ophthalmology referral if patient is symptomatic with cataract or noted to have raised intraocular pressure. If the intraocular pressure is greater

than $30 \mathrm{mmHg}$ the referral should be expedited.

Ensure patients on ethambuto are referred for ophthalmology screening.

Ensure patients on fingolimod are referred for ophthalmolog screening.

Routine ophthalmology referral if symptomatic. 


\begin{tabular}{|c|c|c|c|}
\hline Oral drug & Ocular adverse effects & Management & Action required \\
\hline Pentosan polysulfate & $\begin{array}{l}\text { Pentosan polysulfate maculopathy has been reported } \\
\text { to have an incidence of } 16 \% \text {. Retinal pigment epithelial } \\
\text { lesions are more common with prolonged use and } \\
\text { higher daily and cumulative doses. }{ }^{24}\end{array}$ & $\begin{array}{l}\text { Multimodal retinal imaging can identify pentosan polysulfate } \\
\text { maculopathy before irreversible macular damage has developed. } \\
\text { Patients with cumulative dosages over } 500 \mathrm{~g} \text { should receive annual } \\
\text { ophthalmology assessment and those with cumulative dosages over } \\
1000 \mathrm{~g} \text {, especially over } 1500 \mathrm{~g} \text {, should be monitored for macular toxicity } \\
\text { even more regularly. }\end{array}$ & $\begin{array}{l}\text { Ensure patients on pentosan } \\
\text { polysulfate with a cumulative } \\
\text { dose over } 500 \mathrm{~g} \text { are referred for } \\
\text { ophthalmology screening. }\end{array}$ \\
\hline Phenothiazines & $\begin{array}{l}\text { High doses result in abnormal pigmentation of the } \\
\text { eyelids, conjunctiva and cornea. }{ }^{25} \\
\text { High doses have been reported to cause corneal } \\
\text { epithelial changes. }{ }^{25} \\
\text { A rare but serious adverse effect is development of } \\
\text { corneal oedema. }\end{array}$ & $\begin{array}{l}\text { Epithelial keratopathy does not usually cause any visual impairment and } \\
\text { normally clears after stopping the drug. } \\
\text { Corneal oedema may result in irreversible visual impairment if the drug } \\
\text { is not stopped promptly. }{ }^{25}\end{array}$ & $\begin{array}{l}\text { Immediate ophthalmology referral } \\
\text { in symptomatic patients. }\end{array}$ \\
\hline $\begin{array}{l}\text { Phosphodiesterase type } 5 \\
\text { inhibitors } \\
\text { - sildenafil } \\
\text { - tadalafil }\end{array}$ & $\begin{array}{l}\text { A bluish discoloration of vision may occur 1-2 hours } \\
\text { after ingestion. }{ }^{26} \\
\text { Persistent blurred vision has been reported secondary } \\
\text { to non-arteritic ischaemic optic neuropathy, } \\
\text { cilioretinal artery occlusion, or central serous } \\
\text { chorioretinopathy. } .^{27,28}\end{array}$ & $\begin{array}{l}\text { Consider discussing this potential ocular adverse event when } \\
\text { prescribing or dispensing. }\end{array}$ & $\begin{array}{l}\text { Routine ophthalmology } \\
\text { referral if any persisting visual } \\
\text { symptoms. }{ }^{27,28}\end{array}$ \\
\hline Tamoxifen & $\begin{array}{l}\text { Intraretinal crystalline deposits, macular oedema } \\
\text { and punctate retinal pigmentary changes have } \\
\text { been reported. }{ }^{29-32} \\
\text { The degree of toxicity is related to the dose and } \\
\text { duration of tamoxifen use. }{ }^{30}\end{array}$ & $\begin{array}{l}\text { Systematic screening of all symptom-free patients taking the lower } \\
\text { dose ( } 20-40 \mathrm{mg} \text { a day) for metastatic breast cancer has not been } \\
\text { shown to be of high yield in detecting ocular toxity. }{ }^{31} \text { However, routine } \\
\text { ophthalmological assessment is reasonable in asymptomatic patients } \\
\text { on higher doses, treatment for more than } 5 \text { years or pre-existing } \\
\text { macular disease. }{ }^{32} \\
\text { Early crystalline maculopathy without visual symptoms does not } \\
\text { always require stopping the drug. Alternative oncological therapies } \\
\text { are available if serious ocular complications arise. }\end{array}$ & $\begin{array}{l}\text { Baseline ophthalmology } \\
\text { assessment and regular } \\
\text { monitoring in high-risk groups. } \\
\text { Immediate ophthalmology referral } \\
\text { in symptomatic patients. }\end{array}$ \\
\hline $\begin{array}{l}\text { Tetracyclines } \\
\text { - doxycycline } \\
\text { - tetracycline }\end{array}$ & $\begin{array}{l}\text { Nausea, vomiting and morning headaches may be } \\
\text { symptoms of idiopathic intracranial hypertension } \\
\text { which can lead to permanent loss of vision. }{ }^{33}\end{array}$ & $\begin{array}{l}\text { Consider discussing the symptoms of idiopathic intracranial } \\
\text { hypertension when prescribing or dispensing this medication. }\end{array}$ & $\begin{array}{l}\text { Urgent ophthalmology referral if } \\
\text { patient is symptomatic. }\end{array}$ \\
\hline $\begin{array}{l}\text { Thiazolidinediones } \\
\text { (glitazones) } \\
\text { - pioglitazone } \\
\text { - rosiglitazone }\end{array}$ & May result in development of macular oedema. ${ }^{34,35}$ & Consider an alternative drug in patients with diabetic retinopathy. ${ }^{34,35}$ & $\begin{array}{l}\text { Diabetic retinopathy screening } \\
\text { as per national guidelines and } \\
\text { immediate ophthalmic referral in } \\
\text { symptomatic patients. }\end{array}$ \\
\hline
\end{tabular}




\section{Table 2 Symptoms associated with disease of different parts of the eye}

\begin{tabular}{ll}
\hline Disease & Symptoms \\
\hline Angle-closure glaucoma & Ocular pain, haloes around lights, nausea and vomiting \\
\hline Corneal disease & Photophobia, grittiness, ocular pain, blurred vision \\
$\begin{array}{l}\text { Ocular inflammation } \\
\text { (uveitis, scleritis) }\end{array}$ & Photophobia, blurred vision, ocular pain, floaters \\
\hline Cataract & Constant clouded, blurred and dim vision, glare (for \\
\hline Macular disease & Distortion, central scotoma, blurred vision, difficulty reading \\
\hline Optic neuropathy & $\begin{array}{l}\text { Impaired colour vision, red desaturation, blurred vision, } \\
\text { field defect }\end{array}$ \\
\hline
\end{tabular}

\section{Fig. Examples of drugs affecting different parts of the eye}

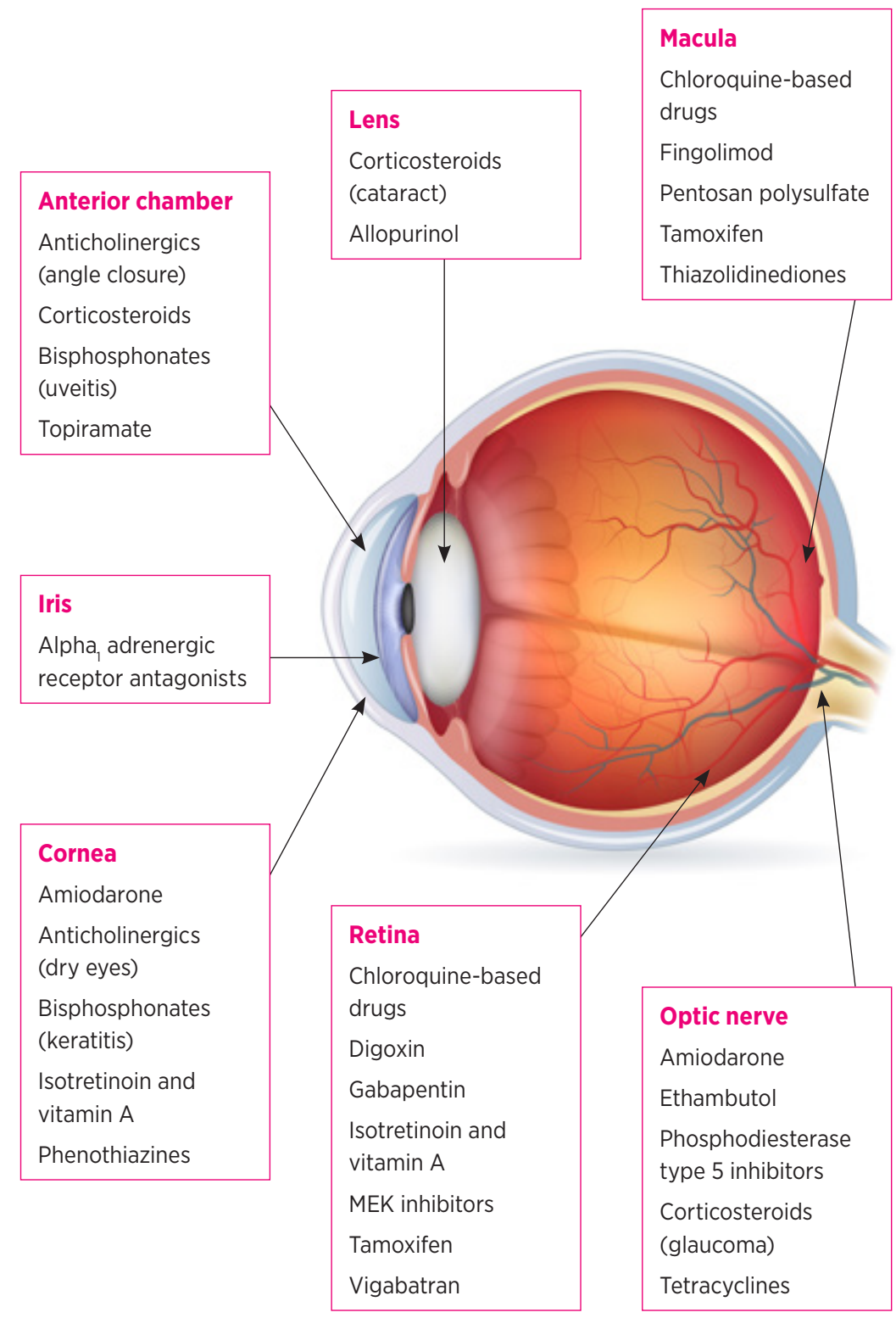

capsule damage during intraocular surgery. Usually there is no need to stop the drug as stopping it does not necessarily prevent floppy iris syndrome. Instead, the ophthalmic surgeon should be informed so they can take appropriate precautions during cataract surgery.

\section{Retina}

Chloroquine and hydroxychloroquine can cause degeneration of the retina and retinal pigment epithelium..$^{15-17,36}$ The risk of toxicity is increased with higher doses and a longer duration of treatment. Additional risk factors are renal or liver impairment or concomitant tamoxifen use. Toxicity can lead to reduced visual acuity, paracentral scotomas and bull's eye (parafoveal) maculopathy. Retinopathy does not always develop in a bull's eye pattern as a more peripheral paracentral pattern of damage can be observed in patients of Asian backgrounds. As a result, screening practices need to be adjusted to recognise both paracentral and parafoveal retinopathy. The damage may be irreversible. Ocular screening during treatment is therefore recommended (Table 1). 15-17,36,37

Tamoxifen retinal toxicity can cause symptoms of decreased visual acuity and colour vision with signs of intraretinal crystalline deposits, macular oedema and punctate retinal pigment epithelial changes. These adverse effects usually occur with higher doses of the tamoxifen (Table 1). ${ }^{29-32}$

Digoxin can cause ocular symptoms including yellowing of vision, scintillating scotoma and blurred vision. These changes are likely to be due to direct photoreceptor toxicity. ${ }^{4}$ The visual symptoms usually reverse when digoxin is discontinued.

Fingolimod, used in the management of multiple sclerosis, has secondary effects on the function of the vascular-endothelial barrier, thereby potentially compromising the blood-retina barrier. Fingolimodassociated macular oedema can cause blurred vision, distortion and impaired reading vision. ${ }^{21}$ Patients with fingolimod-associated macular oedema do not always have to stop treatment because of the risk of a flareup of the multiple sclerosis. The macular oedema can often be treated with ocular therapy.

New ocular adverse effects are being identified with the increased use of oral immune-based therapies such as kinase inhibitors. These include visual disturbances, visual field defects as well as retinal vein occlusion and MEK-associated retinopathy. Communication between the physician and ophthalmologist is important if ocular adverse effects are suspected. ${ }^{23}$

Thiazolidinediones, such as pioglitazone, have been associated with systemic fluid retention. These drugs can worsen diabetic macular oedema, especially in patients with pre-existing diabetic retinopathy. ${ }^{6,34,35}$ 
Drugs for erectile dysfunction, such as sildenafil, can inhibit photoreceptor function. This may cause transient blurring of vision or altered colour perception. There have also been reports of nonarteritic ischaemic optic neuropathy, cilioretinal artery occlusion and central serous chorioretinopathy. ${ }^{26-28}$ Routine referral to an ophthalmologist is required if there are persisting visual symptoms.

Central serous chorioretinopathy is characterised by the accumulation of fluid in the central vision of patients. Symptoms include blurred central vision, distortion and washing out of colours. Central serous chorioretinopathy is associated with systemic steroid use and has been reported with sildenafil.

Vigabatrin has been associated with the development of visual field constriction. Patients may not notice any visual field loss until the central field is affected. The visual field defects do not reverse when the drug is stopped and may worsen with continued use. Hence, a computerised visual field assessment is usually obtained before treatment and is repeated every six months for five years. This can then be extended to an annual review if the patient does not have any visual field defects. ${ }^{13}$

\section{Optic nerve}

Amiodarone may rarely induce optic neuropathy. ${ }^{3}$ This is characterised by swelling of the optic discs in addition to the typical symptoms of optic neuropathy (Table 2). The main differential diagnosis is nonarteritic anterior ischaemic optic neuropathy, which is more common in patients with vasculopathy and is associated with an altitudinal monocular visual field defect (superior or inferior half of the vision is affected).

Tetracyclines have been reported to cause idiopathic intracranial hypertension which in some instances can lead to permanent loss of vision. ${ }^{33}$ Nausea, vomiting and morning headaches, as well as the symptoms of optic neuropathy (Table 2), can be suggestive of idiopathic intracranial hypertension.

Ethambutol can cause optic neuropathy. Animal studies have suggested retinal ganglion cells are predominantly affected. ${ }^{32}$ Risk factors include higher doses, prolonged use, poor renal function and concurrent antiretroviral therapy.

\section{Management of ocular adverse effects}

Consultation with an ophthalmologist is recommended if a drug is suspected to be affecting a patient's vision. Interventions can include screening before treatment, monitoring for ocular toxicity, reducing drug doses, or stopping the drug and looking for an alternative. Some ocular adverse effects such as raised intraocular pressure can be managed with medical or laser therapy. Cataracts can be managed with surgical intervention. However, some ocular adverse events such as macular atrophy can cause irreversible visual loss, hence the need to screen for damage at an early stage.

\section{Pharmacovigilance}

Medicine is a constantly evolving field with new drugs being developed all the time. Many ocular adverse effects are reported during the clinical trials of drug development but others emerge later. Postmarketing surveillance, such as the Black Triangle Scheme, has proved to be valuable in the identification of rare and otherwise not previously reported adverse effects. It is important to keep an open mind when prescribing new drugs and be vigilant in assessing any possible ocular adverse effects. Adverse events should be reported to the Therapeutic Goods Administration.

\section{Conclusion}

Commonly used oral drugs can cause ocular adverse effects. As well as retinal toxicity, oral drugs can affect other parts of the eye including the cornea, lens and optic nerve. Consider drugs as a possible cause of unexplained ocular symptoms. Communication between the prescribing clinician and ophthalmologist will facilitate the best possible patient care. $\varangle$

Conflicts of interest: none declared

\section{REFERENCES}

1. Santaella RM, Fraunfelder FW. Ocular adverse effects associated with systemic medications : recognition and management. Drugs 2007;67:75-93. https://doi.org/ 10.2165/00003495-200767010-00006

2. Fung $A$, McCluskey P. Tamsulosin-induced intraoperative floppy iris syndrome during cataract surgery. Aust Prescr 2010;33:88-9. https://doi.org/10.18773/austprescr.2010.042

3. Nagra PK, Foroozan R, Savino PJ, Castillo I, Sergott RC. Amiodarone induced optic neuropathy. $\mathrm{Br} J$ Ophthalmol 2003;87:420-2. https://doi.org/10.1136/bjo.87.4.420

4. Renard D, Rubli E, Voide N, Borruat FX, Rothuizen LE. Spectrum of digoxin-induced ocular toxicity: a case report and literature review. BMC Res Notes 2015:8:368. https://doi.org/10.1186/s13104-015-1367-6

5. Luo C, Chen X, Jin H, Yao K. The association between gout and cataract risk: A meta-analysis. PLoS One 2017;12:e0180188. https://doi.org/10.1371/journal.pone.0180188

6. Yang MC, Lin KY. Drug-induced acute angle-closure glaucoma: a review. J Curr Glaucoma Pract 2019;13:104-9. https://doi.org/10.5005/jp-journals-10078-1261

7. Sekeroglu MA, Hekimoglu E, Anayol MA, Tasci Y, Dolen I. An overlooked effect of systemic anticholinergics: alteration on accommodation amplitude. Int J Ophthalmol 2016;9:743-5. https://doi.org/10.18240/ijo.2016.05.19

8. Shieh WS, Sridhar J, Hong BK, Maguire JI, Rahimy E, Shahlaee A, et al. Ophthalmic complications associated with direct oral anticoagulant medications. Semin Ophthalmol 2017;32:614-9. https://doi.org/10.3109/08820538.2016.1139738 
9. Hesami O, Hosseini SS, Kazemi N, Hosseini-Zijoud SM, Moghaddam NB, Assarzadegan F, et al. Evaluation of ocular side effects in the patients on topiramate therapy for control of migrainous headache. J Clin Diagn Res 2016;10:NC01-04. https://doi.org/10.7860/JCDR/2016/16263.7339

10. Abtahi MA, Abtahi SH, Fazel F, Roomizadeh P, Etemadifar M, Jenab K, et al. Topiramate and the vision: a systematic review. Clin Ophthalmol 2012;6:117-31. https://doi.org/10.2147/ OPTH.S27695

11. Craig JE, Ong TJ, Louis DL, Wells JM. Mechanism of topiramate-induced acute-onset myopia and angle closure glaucoma. Am J Ophthalmol 2004;137:193-5. https://doi.org/ 10.1016/S0002-9394(03)00774-8

12. Quintero GC. Review about gabapentin misuse, interactions, contraindications and side effects. J Exp Pharmacol 2017;9:13-21. https://doi.org/10.2147/JEP.S124391

13. Hawker MJ, Astbury NJ. The ocular side effects of vigabatrin (Sabril): information and guidance for screening. Eye (Lond) 2008;22:1097-8. https://doi.org/10.1038/eye.2008.139

14. McKague M, Jorgenson D, Buxton KA. Ocular side effects of bisphosphonates: A case report and literature review. Can Fam Physician 2010;56:1015-7.

15. Grierson DJ. Hydroxychloroquine and visual screening in a rheumatology outpatient clinic. Ann Rheum Dis 1997:56:188-90. https://doi.org/10.1136/ard.56.3.188

16. Browning DJ. Hydroxychloroquine and chloroquine retinopathy: screening for drug toxicity. Am J Ophthalmo 2002;133:649-56. https://doi.org/10.1016/S0002-9394(02)01392-2

17. Michaelides M, Stover NB, Francis PJ, Weleber RG. Retinal toxicity associated with hydroxychloroquine and chloroquine: risk factors, screening, and progression despite cessation of therapy. Arch Ophthalmol 2011;129:30-9. https://doi.org/10.1001/archophthalmol.2010.321

18. Mavrikakis I, Sfikakis PP, Mavrikakis E, Rougas K, Nikolaou A, Kostopoulos C, et al. The incidence of irreversible retinal toxicity in patients treated with hydroxychloroquine: a reappraisal. Ophthalmology 2003;110:1321-6. https://doi.org/ 10.1016/S0161-6420(03)00409-3

19. Jones R 3rd, Rhee DJ. Corticosteroid-induced ocular hypertension and glaucoma: a brief review and update of the literature. Curr Opin Ophthalmol 2006;17:163-7. https://doi.org/10.1097/01.icu.0000193079.55240.18

20. Chamberlain PD, Sadaka A, Berry S, Lee AG. Ethambutol optic neuropathy. Curr Opin Ophthalmol 2017;28:545-51. https://doi.org/10.1097/ICU.0000000000000416

21. Jain N, Bhatti MT. Macular edema associated with fingolimod. EyeNet Magazine May 2021. www.aao.org/ eyenet/article/macular-edema-associated-with-fingolimod [cited $2021 \mathrm{Jul} 1]$

22. Fraunfelder FT, Fraunfelder FW, Edwards R. Ocular side effects possibly associated with isotretinoin usage. Am J Ophthalmol 2001;132:299-305. https://doi.org/10.1016/ S0002-9394(01)01024-8

23. Méndez-Martínez S, Calvo P, Ruiz-Moreno O, Pardiñas Barón N, Leciñena Bueno J, Gil Ruiz MD, et al. Ocular adverse events associated with MEK inhibitors. Retina 2019;39:1435-50. https://doi.org/10.1097/ IAE.0000000000002451
24. Wang D, Velaga SB, Grondin C, Au A, Nittala M, Chhablani J, et al. Pentosan polysulfate maculopathy: prevalence, spectrum of disease, and choroidal imaging analysis based on prospective screening. Am J Ophthalmol 2021;227:125-38. https://doi.org/10.1016/j.ajo.2021.02.025

25. Richa S, Yazbek JC. Ocular adverse effects of common psychotropic agents: a review. CNS Drugs 2010;24:501-26. https://doi.org/10.2165/11533180-000000000-00000

26. Moschos MM, Nitoda E. Pathophysiology of visual disorders induced by phosphodiesterase inhibitors in the treatment of erectile dysfunction. Drug Des Devel Ther 2016;10:3407-13. https://doi.org/10.2147/DDDT.S118015

27. Hayreh SS. Erectile dysfunction drugs and non-arteritic anterior ischemic optic neuropathy: is there a cause and effect relationship? J Neuroophthalmol 2005;25:295-8. https://doi.org/10.1097/01.wno.0000189059.90057.98

28. Karaarslan C. Ocular side effects of sildenafil that persist beyond $24 \mathrm{~h}$ - a case series. Front Neurol 2020;11:67. https://doi.org/10.3389/fneur.2020.00067

29. Alwitry A, Gardner I. Tamoxifen maculopathy. Arch Ophthalmol 2002;120:1402. https://doi.org/10.1001/ archopht.120.10.1402

30. Nayfield SG, Gorin MB. Tamoxifen-associated eye disease. A review. J Clin Oncol 1996;14:1018-26. https://doi.org/ 10.1200/JCO.1996.14.3.1018

31. Heier JS, Dragoo RA, Enzenauer RW, Waterhouse WJ. Screening for ocular toxicity in asymptomatic patients treated with tamoxifen. Am J Ophthalmol 1994;117:772-5. https://doi.org/10.1016/S0002-9394(14)70321-6

32. Therssen R, Jansen E, Leys A, Rutten J, Meyskens J. Screening for tamoxifen ocular toxicity: a prospective study. Eur J Ophthalmol 1995;5:230-4. https://doi.org/10.1177/ 112067219500500406

33. Digre KB. Not so benign intracranial hypertension. BMJ 2003;326:613-4. https://doi.org/10.1136/bmj.326.7390.613

34. Idris I, Warren G, Donnelly R. Association between thiazolidinedione treatment and risk of macular edema among patients with type 2 diabetes. Arch Intern Med 2012;172:1005-11. https://doi.org/10.1001/ archinternmed.2012.1938

35. Ryan EH Jr, Han DP, Ramsay RC, Cantrill HL, Bennett SR, Dev S, et al. Diabetic macular edema associated with glitazone use. Retina 2006;26:562-70. https://doi.org/ 10.1097/00006982-200605000-00011

36. Royal College of Ophthalmologists. Hydroxychloroquine and chloroquine retinopathy: recommendations on monitoring 2020. Updated 2020 Dec 16. www.rcophth.ac.uk/2020/12/ hydroxychloroquine-and-chloroquine-retinopathyrecommendations-on-monitoring [cited 2021 Jul 1]

37. Royal Australian and New Zealand College of Ophthalmologists. Guidelines for screening for hydroxychloroquine retinopathy. Sydney: RANZCO; 2015 https://ranzco.edu/wp-content/uploads/2021/04/RANZCOGuidelines-for-screening-for-HCQ-Retinopathy-1.pdf [cited $2021 \mathrm{Jul} 1]$ 